\title{
Survey on Women's Modern Self-Defense Gadgets
}

\author{
Madhura K \\ Assistant Professor, Presidency University, Bangalore
}

\begin{abstract}
Even if India is on the way to a modern country, the thinking about women's is still the same in many states. Women's are as educated as men's and as successful as men's but working and travelling of women's in late night is a still a concern. How they can save themselves from kidnapping and raping. Now a day's many modern ready products are available which are wearable and can help in saving a life. For example pepper spray is available everywhere in shops. This paper is a survey on such products which can be used anyone for the purpose of alerting concerned authorities.
\end{abstract}

Keywords: Safelet, Pepper spray pistol, safety torch with shock effect, Safety rod, Personal Alarm Wristlet, Revolar

\section{INTRODUCTION}

Women safety in India is highly compromised which have actually resulted in making India - A Vulnerable Country, especially for women. So, there is a high need for women to be aware of all the self-defense techniques and all the smart apps that are made for women safety. Not only these women safety gadgets can protect you from all the risky situations but they are also easy and safe to carry in your handbag. So lets walk through all the essential women safety gadgets that every independent lady should carry as the mantra is to "Be Safe". Self-defense is incredibly important because staying safe should be everyone's \& their family member's number one priority. Keep at least one of these self defence items handy with you all the time, ideal to ensure your protection while you are at work, college and home security. They will never gather dust on your shelf or purse your true saviors in need.

\section{LITERATURE SURVEY}

1. Safelet: Safelet is wearable women safety device with two buttons on the side that can be used to send a message or contact the guardian member. It also syncs with the user's cell phone to start audio recording. In case of risky situation, the concerned member who receives the alert can immediately dial the emergency number 911 from within the app. The price of the product is INR 9,990 and available in Amazon.

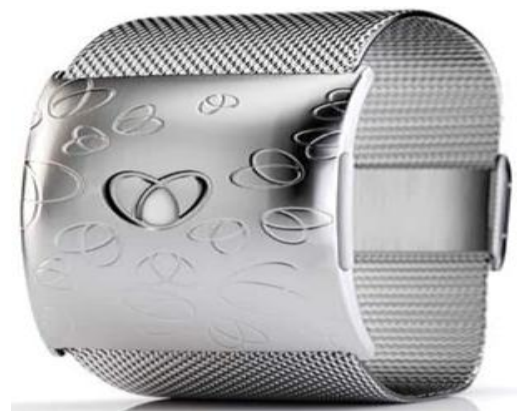

2. Pepper Spray Pistol: Pepper spray pistol is among the legally approved women self-defence appliances.

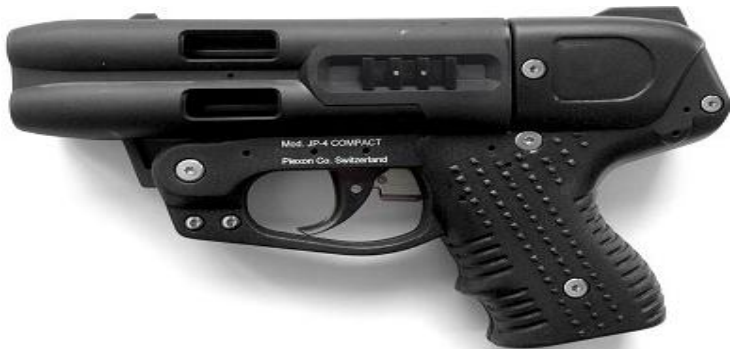




\section{International Advanced Research Journal in Science, Engineering and Technology}

Vol. 5, Issue 11, November 2018

It is way different than other pepper sprays as it doesn't require to be sprayed on eyes. As this spray act as irritant affecting the eyes and skin of the person. Always remember two sprays are capable to affect the attacker. If you spray continuously then the bottle will be emptied in 6 seconds. The price of the product is INR 6,000and available in Pepper Spray.

3. Lipstick Shaped Flashlight: Just like the size of the lipstick, this women safety device is of 5 inches. The size makes the device easy to carry and can be secretly kept. The lipstick comes with a rechargeable battery and captures 180 lumens flashlight. Such normal things with secretive powers are actually beneficial for every woman. The price of the product is INR 799 and available in Amazon.

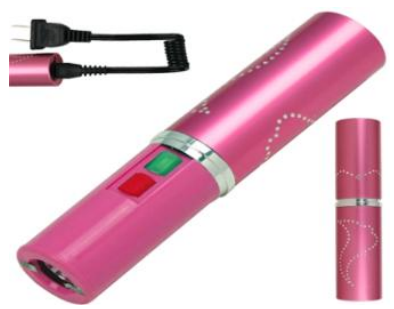

4. Safety Torch With Shock Effect: Rechargeable safety torch with shock effect can be the saviour for women. The LED Flashlight with hidden electricity can shake a person very badly. Such personal protection equipment should be considered as the must carry essential of women's bag. The price of the product is INR 790 and available in Snapdeal.

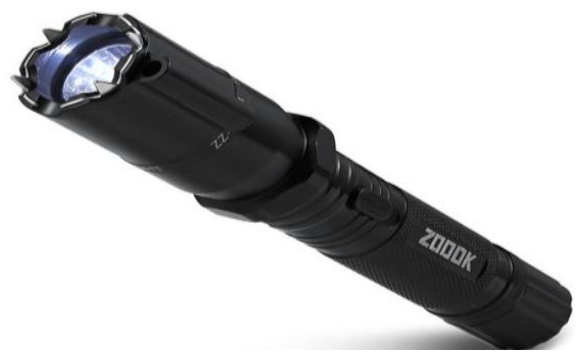

5. Safety Rod: The telescopic batons can be played very well for both offence and defence techniques in self-defense. Safety rods can deliver a massive pain with a shock to the attacker. The simple motto of this device is to save you from all the risky people. The price of the product is INR 790 and available in Amazon.

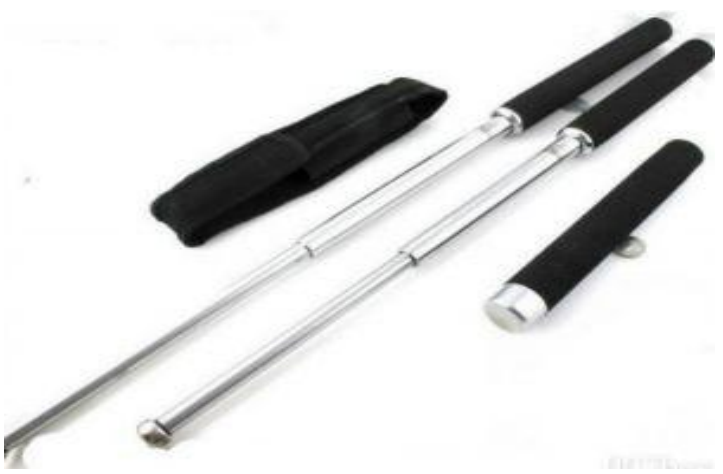

\section{Sonata Watch Named ACT:}

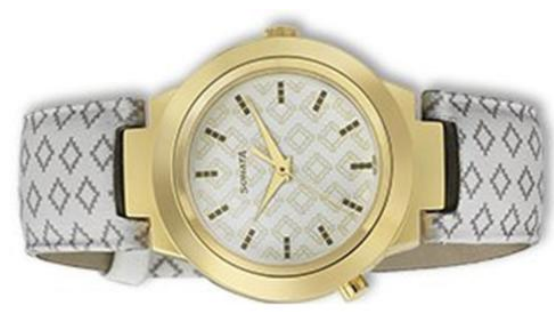




\section{International Advanced Research Journal in Science, Engineering and Technology}

Vol. 5, Issue 11, November 2018

The Sonata Watch ACT has a mobile application which will be downloaded in the user's smartphone. By making use of Bluetooth, the watch will work with the phone to send distress alerts to the network of the guardian member. The alert message in the app and SMS will include user's location. The price of the product is INR2,969 and available in Amazon.

7. Safer Smart Pendant: This pendant is not the normal pendant. As it has a small circular device known as SAFER. Whenever you feel unsafe, just double-click the safer device attached to the pendant. Then automatically an alert will be sent to your family or friends. Because of the GPS function, your location can be sent pin the alert. The price of the product is INR 1,899 and is available in Amazon.

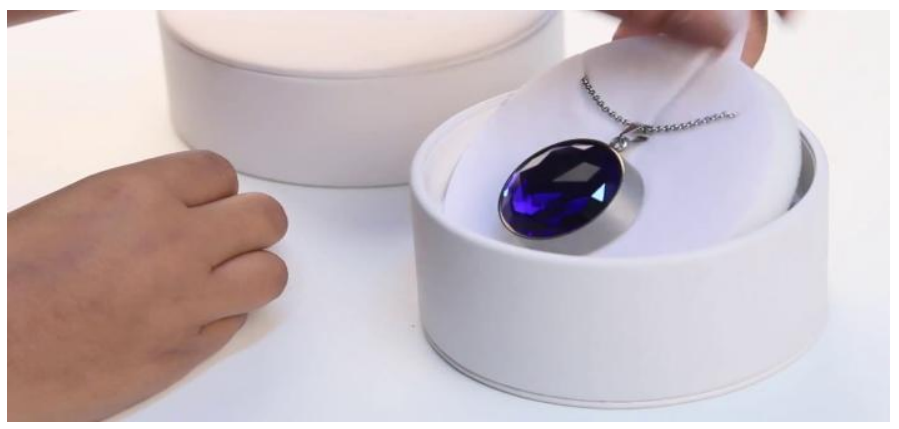

8. Personal Alarm Wristlet With Whistle: Personal Alarm Wristlet with a hidden whistle is specially designed for women safety. It is placed in outer pockets of a purse or backpack and can be hand-carried. The alarm is activated when the pin is pulled and detects the attacker. It also has an LED Light which will never leave you in the dark. The price of the product is INR 450 and is available in Amazon.

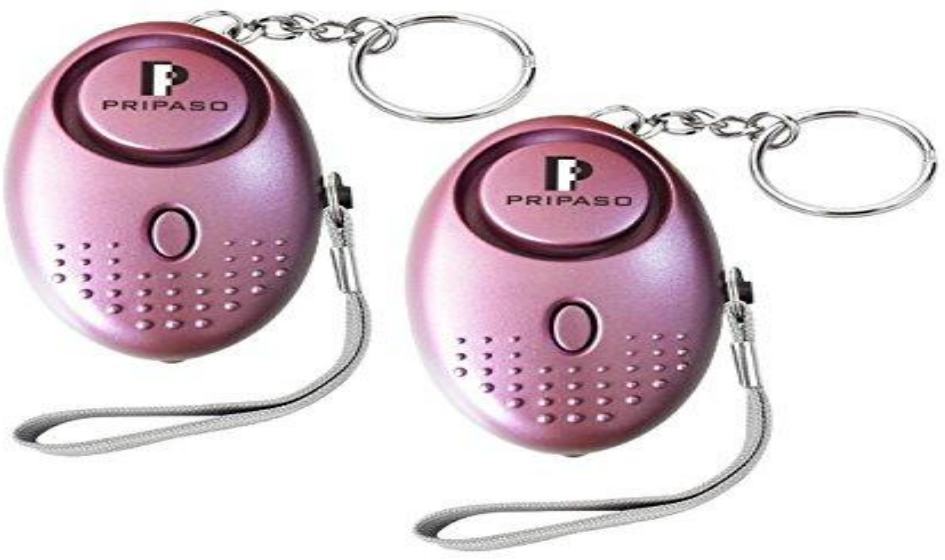

9. Revolar: Revolar is an oval-shaped look like a small garage clicker. It is easily kept onto a jeans pocket or sports bra. When it is pressed twice then it sends a yellow message to the designated contacts with your current location and telling that you are not safe. The red message is sent when the revolar is clicked thrice. So, carry this beneficial women safety device for the protection. The price of the product is INR 6,543 and is available in Amazon.

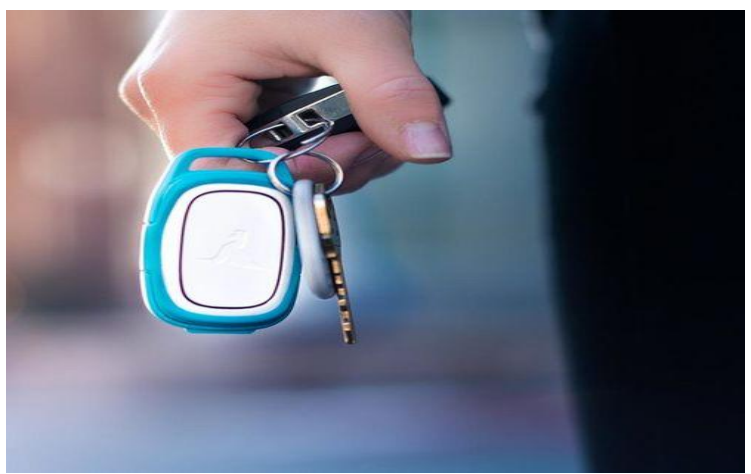




\section{International Advanced Research Journal in Science, Engineering and Technology}

Vol. 5, Issue 11, November 2018

10. Sound Grenade E-Alarm Personal Safety: Sound Grenade is a non-lethal product that loud $120 \mathrm{Db}$ Siren that weighs only 20 Grams. It is created specially to prevent you from thefts, rapes, mugging or any other risky situation by sending an alarm to anyone in the range of sound within 100 meters. The price of the product is INR 999 and is available in Amazon.
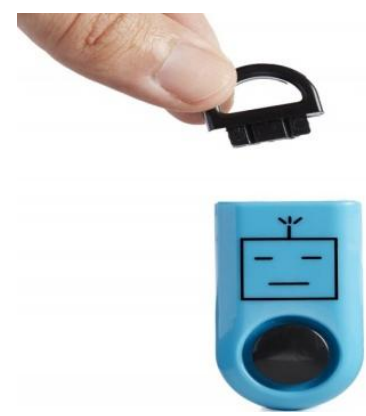

11. Siren: Disguised as an average ring, SIREN actually helps users stay safe by emitting a piercing, loud sound to confuse and distract attackers. The sound is over 110 decibels loud and can be heard from 50 feet away. Users simply twist the top of the ring to the left, approximately 60 degrees, to emit the loud sound. In a little over a second, the sound begins; this delay also allows the user to switch the ring back off in cause the situation doesn't require it anymore. Its stylish design and easy access make it simple to use in variety of situations.

12. Stiletto Charms: In an effort to make the personal safety device more discreet, Stiletto Charms mimic the aesthetic of modern jewelry. They can complement virtually any outfit but secretly manage a variety of functionalities. Using the Stiletto mobile app, users can create an emergency profile, set up emergency contacts, plan a route and check the device's battery level. Besides contacting friends and family members, Stiletto Charms can also reach 911 dispatches in the U.S. - and they even have a voice-assisted alert system to communicate when the user might not be able to speak.

13. Roar(Athena): ROAR for Good created its first product, Athena, to create a simple way for women to get help. Roughly the size of a half dollar coin, Athena activates a loud alarm when users press a button. The device then sends an alert with the location of the user to contacts who can help. The device can be attached to a purse or even worn as a necklace (a recessed button avoids any accidental alarms). Users can also set the device to silent mode so that Athena still sends information to contacts without making a sound.

14. Under Cover Nail-Polish: The main idea behind Undercover Colors, a date rape drug-detecting nail polish, is that a woman wearing it could simply dip a finger in her drink and her nail polish would change color if a date-rape drug (specifically rohypnol or GHB) were detected. Largely geared towards the bar scene, this product could only be an asset to women. Since being announced in 2014, Undercover Colors has been seeking funding and working on research and development, which might have paid off — recent updates to their website and statements from the founders suggest a release is coming soon.

15. The personal alarm: Though very small, this device can scream very loudly at the push of a button. So, when you are attacked, you can use it to attract attention. The loud scream alone can discourage attackers, as it continues until you stop it. Some personal alarms even have in-built light, which helps you find objects or your way through the dark.

16. The mace spray: This tube-like device, like the pepper spray, causes inflammation of the eye capillaries and temporary visual impairment. It also causes choking, sneezing, and severe burning sensation to the eyes, nose, and throat. However, these effects are not permanent.

17. The TASER device: This personal protection device can stun an attacker from a distance of about 15 feet away. Yet, it doubles as a powerful contact stun device. The device is very easy to use because hitting it anywhere on the attacker's body will render him incapacitated. This is quite unlike pepper sprays and other self-defense devices, all of which must be targeted directly at the assailant's face for any effect to be produced.

18. The tear gas spray: This device, as the name implies, contains tear gas, which is notorious for its irritating effect on the eyes, nose, and throat. However, the tear gas spray is less effective than the pepper spray.

19. The ultrasonic dog repellant: Using this device is the safest and most lenient way to deter aggressive dogs. It emits sound waves of very high frequencies $(20,000 \mathrm{~Hz}-25,000 \mathrm{~Hz})$. The sound produced cannot be heard by humans, but can be heard by dogs and cats. Just press the power button and point it in the direction of the approaching dog, and 


\section{International Advanced Research Journal in Science, Engineering and Technology}

Vol. 5, Issue 11, November 2018

it will be irritated and chased away by the ultrasonic sound produced by the device. However, the ultrasonic dog repeller will not repel human attackers; it only helps to establish a safe zone between you and hostile dogs.

In conclusion, it is very important you keep in mind that the best protection you can give yourself is to avoid potentially dangerous situations as much as possible. After all, it is often said that prevention is better than cure. So try as much as possible to avoid being a victim of crime, and a great way to achieve this is to have a high level of security awareness or consciousness.

20. Spy Mobile Stun Gun: Spy Mobile Stun Gun is a guarding tool which ensures personnel protection from any threat or danger. The Mobile Stun Gun produces high voltage beam as directed by the user to keep enemy or danger away.

\section{ANALYSIS}

Rape is the fourth most common crime in India. According to the National Crime Records Bureau 2013 annual report, 24,923 rape cases were reported across India in 2012. Out of these, 24,470 were committed by someone known to the victim (98\% of the cases). India has been characterized as one of the "countries with the lowest per capita rates of rape". A large number of rapes go unreported. The willingness to report the rape has increased in recent years, after several incidents of rape received widespread media attention and triggered public protest. This led the Government of India to reform its penal code for crimes of rape and sexual assault. According to Rediff Labs, Madhya Pradesh reported the highest number of rape cases $(3,425)$, Rajasthan ranks second with 2,049 cases followed by West Bengal $(2,046)$ and Uttar Pradesh (1,963). Mizoram constituency has the highest incidence of rape in the country $(94$ cases per million population), Chandni Chowk comes second (86 cases per million) and third is Shillong constituency (81 cases per million).

1. In past 10 years, rape cases against juveniles jump $300 \%$ : Incidents of rapes allegedly committed by juveniles rose from 466 in 2003 to 1,884 in 2013 — an increase of $304.3 \%$. The highest incidence of the rape cases, committed by juveniles, was reported from Madhya Pradesh followed by Maharashtra.

2. 22,172 rapes in $2010 ; 24,923$ in 2012: According to Wikipedia the following number of rapes took place in India in the years between 2004 and 2010

\begin{tabular}{|c|l|l|l|l|l|l|}
\hline 2004 & 2005 & 2006 & 2007 & 2008 & 2009 & 2010 \\
\hline 18233 & 18359 & 19348 & 20737 & 21467 & 21397 & 22172 \\
\hline
\end{tabular}

If we take the 2010 figure, the highest of these seven years (2004-2010), it works out to 60.7 rapes a day; 2.53 rapes every hour; or one rape every 23.7 minutes, in a country of 1.2 billion people.

\section{Some Sample Reported Cases:}

- A Class 12 student allegedly raped a Class 9 student - a 15 year old — inside school premises in outer Delhi's Rohini area last month.

- A 16-year-old girl was allegedly gang raped by five people at knife point in East Delhi's Madhu Vihar in August this year and two of the accused arrested were juveniles.

These are not isolated incidents of juveniles in conflict with the law. Rather, the incidents allude to a worrying trend of rising juvenile crime graph across the country. According to National Crime Records Bureau (NCRB), juvenile crime rose by $78 \%$ during 2003-13. But their involvement in crime against women has increased alarmingly.

Incidents of rapes allegedly committed by juveniles rose from 466 in 2003 to 1,884 in 2013 - an increase of $304.3 \%$. The highest incidence of the rape cases, committed by juveniles, in the country was reported from Madhya Pradesh (347) followed by Maharashtra (197), Uttar Pradesh (196) and Rajasthan (183) which was 18.4\%, 10.5\% and 10.4\% of total rape cases committed by juveniles respectively in the country. Among UTs, 137 cases of rape by juveniles were reported in Delhi during the year 2013.

As against 158 cases of kidnapping of women and girls registered in 2003 against juveniles, 969 such cases were lodged against them in 2013 — an increase of $513.3 \%$. Cases of outraging modesty of women allegedly committed by juveniles too witnessed a sharp increase of $172.8 \%$ during the decade — from 522 to 1424 . 


\section{International Advanced Research Journal in Science, Engineering and Technology}

Vol. 5, Issue 11, November 2018

Juveniles' involvement in other heinous crimes - such as murder, kidnapping and robbery too rose sharply. Murder was up from 465 in 2003 to 1007 — an increase of $116.6 \%$. Kidnapping rose $455 \%$ during the decade - from 202 in 2003 to 1121 in 2013 while robbery rose by 334.6\% from 208 in 2003 to 904 in 2013.

- A sample chart which shows the statistics of rape count from 2003 to 2011 is shown below:

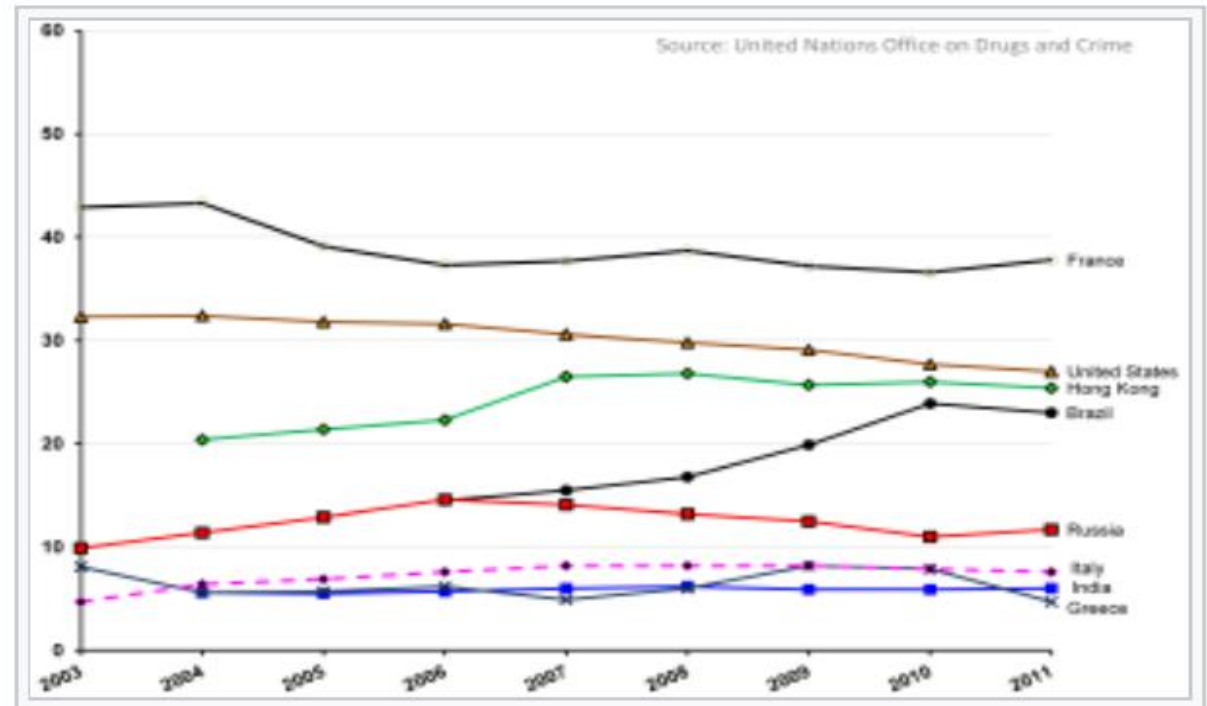

CONCLUSION

It is identified as in India for every one hour there will be two rape victims on average. Most of the cases gets not reported or unnoticed. It is very much important that if women's become strong in self-defence too along with being independent. Many are unaware of the readily available products for the self-defence. This survey makes an attempt to make learners to give a knowledge about it. As none of the things in the world meets $100 \%$, these products are just a plus point to ladies along with this it will be better have a strong will power and learn some martial arts as a selfdefence art.

\section{REFERENCES}

[1]. https://www.hindustantimes.com/india/in-past-10-years-rape-cases-against-juveniles-jump-300/story-OiDq04bWBDcU5RucvfZepM.html

[2]. https://en.wikipedia.org/wiki/Rape_in_India

[3]. http://indpaedia.com/ind/index.php/Rapes_in_India:_annual_statistics

[4]. https://www.rediff.com/travel-living/report/7-highly-effective-self-defence-accessories-for-women/20150325.htm

[5]. https://www.expertsecuritytips.com/best-personal-protection-devices-for-women/

[6]. http://www.chipchick.com/2018/03/personal-safety-devices.html

[7]. https://magicpin.in/blog/top-10-woman-safety-gadgets/ 